\title{
The comorbidity of increased arterial stiffness and microalbuminuria in a survey of middle-aged adults in China
}

\author{
Rujia Miao', Liuxin $\mathrm{Wu}^{2}$, Ping $\mathrm{Ni}^{3}$, Yue Zeng ${ }^{1}$ and Zhiheng Chen ${ }^{1 *}$ (B)
}

\begin{abstract}
Background: Increased arterial stiffness (iAS) and microalbuminuria (MAU), which may occur simultaneously or separately in the general population and share similar risk factors, are markers of macro- and microvascular injuries. Our research investigated the comorbidity of IAS and MAU in the middle-aged population and examined the heterogeneous effects of metabolic risk factors on iAS and MAU.

Methods: We selected 11,911 individuals aged 45 to 60 years who underwent a health examination at the 3rd Xiangya Hospital between 2010 and 2014. Metabolic syndrome (MetS) was determined according to IDF/ $\mathrm{NHLBI/AHA-2009}$ criteria. Multinomial logistic regression was applied to evaluate the influence of MetS, components of MetS and clusters of MetS on the co-occurrence (MAU(+)/iAS(+)) or non-co-occurrence (MAU(+)/iAS(-) and MAU(-)/ iAS(+)) of MAU and iAS.

Results: Reference group was MAU(-)/iAS(-). A positive effect of MetS on the presence of MAU(+)/iAS(-), MAU(-)/ $\mathrm{iAS}(+)$, or MAU(+)/iAS(+) is listed in ascending order based on odds ratios (ORs $=2.11,2.41,4.61$, respectively; $P<0.05)$. Compared with MAU(+)/iAS(-), Elevated blood pressure (BP) $(\mathrm{OR}=1.62$ vs. $4.83, P<0.05)$, triglycerides $(\mathrm{TG})(\mathrm{OR}=1.20$ vs. $1.37, P<0.05)$ were more strongly associated with $\mathrm{MAU}(-) / \mathrm{iAS}(+)$, whereas fasting blood glucose $(\mathrm{FBG})$ was less associated $(\mathrm{OR}=1.37$ vs. 1.31, $P<0.05)$. Decreased high-density lipoprotein cholesterol(HDL-c) $(O R=1.84, P<0.01)$ and elevated waist circumference(WC) $(\mathrm{OR}=1.28 P<0.01)$ were the most strongly associated with $\mathrm{MAU}(+) / \mathrm{AAS}(-)$. Compared with the individuals without MetS, individuals with the elevated BP, FBG, TG and decreased HDL-c cluster had the greatest likelihood of presenting a MAU(-)/iAS(+) $(\mathrm{OR}=5.98, P<0.01)$ and $\mathrm{MAU}(+) / \mathrm{iAS}(+)(\mathrm{OR}=13.17, P<0.01)$, these likelihood was even greater than the cluster with simultaneous alteration in all five MetS components ( $O R=3.89$ and 10.77, respectively, $P<0.01)$, which showed the most strongly association with $M A U(+) / A A S(+)(O R=5.22, P<0.01)$.
\end{abstract}

Conclusion: Based on the heterogeneous influences of MetS-related risk factors on MAU and iAS, these influences could be selectively targeted to identify different types of vascular injuries.

Keywords: Arterial stiffness, Microalbuminuria, Metabolic syndrome

\section{Background}

Increased arterial stiffness (iAS) and microalbuminuria (MAU) are surrogate markers of macro [1] - and microvascular [2] damages, respectively; however, their comorbidity in the general population is unknown.

The formation of MAU is due to the leaking of small amounts of albumin from kidney into the urine [2], this

\footnotetext{
* Correspondence: chenzhiheng_health@163.com

'Department of Health Management, the Third Xiangya Hospital, Central South University, Tongzipo Road 138, Changsha 410013, Hunan Province, China

Full list of author information is available at the end of the article
}

reversible indicator is initiated by endothelial dysfunction and becomes fixed with the progression of renal microvascular abnormality [2]. iAS occurs as a consequence of biological aging [3] and arteriosclerosis [4], and pulse wave velocity is measured as a sign of macroangiopathy that reflects functional changes [5].

As two early markers of micro- and macrovascular complications $[6,7]$, there are connections between MAU and iAS: evidence has indicated that arterial stiffness is associated with MAU in patients with diabetes or hypertension [8] and in the general population $[9,10]$,

(C) The Author(s). 2018 Open Access This article is distributed under the terms of the Creative Commons Attribution 4.0 International License (http://creativecommons.org/licenses/by/4.0/), which permits unrestricted use, distribution, and 
and further study suggested that higher arterial stiffness is an independent risk factor for MAU [11]. Additionally, both iAS [12] and MAU [13] can be affected by similar factors: age [14-16]; gender $[15,17,18]$; and metabolic abnormalities, such as impaired glucose tolerance [16, 17, 19], high blood pressure $[15,16,20]$, dyslipidemia $[15,16]$, and obesity $[15,21]$.

As manifestations of vascular damage in different areas $[1,2]$, since iAS and MAU have correlation and share common risk factors mentioned above, we hypothesize that taken together, iAS and MAU may represent a continuum in some populations; that is, individuals with less severe vascular disease express only one of these markers, while individuals with more severe disease express both. Systematic screening of this continuum is lacking in adults despite its potentially high utility in predicting vascular mortality; consequently, research regarding modifiable metabolic risk factors for MAU and iAS could be important for developing effective public health care initiatives.

The aims of our study were to measure the comorbidity of elevated MAU and iAS in the middle-aged population to determine whether MAU and iAS share a common pattern of individual risk factors for metabolic syndrome.

\section{Methods}

\section{Study population and measurements}

A cross-sectional study was conducted in a general population. The medical records of 11,911 participants from Central South China who underwent a health check at the Health Examination Management Center of the 3rd Xiangya Hospital from January 1, 2010, to October 31, 2014, were reviewed by trained staff. The inclusion criteria were as follows: age between 45 and 60 years and Han ethnicity. The exclusion criteria were heart failure, chronic nephritis, renal insufficiency, and pregnancy. The history of medication, smoking and cardiovascular disease was reviewed.

We only included middle-aged participants because vascular aging is common in older people [22]. This study was conducted according to the principles expressed in the Declaration of Helsinki and was approved by the Ethics Committee of the Third Xiangya Hospital, and the consent form was signed by each participant.

Waist circumference (WC) was measured by wrapping a measuring tape completely around the waist $0.5 \mathrm{~cm}$ above the belly button [23]. Systolic and diastolic blood pressure (SBP and DBP) was measured between 8 AM and 10 AM,following the guidelines from the American Health Association [24], all measurement were conducted using an automatic digital BP monitor(Omron 9020), with the participants seated after a 10-min rest period, with feet straight upon the ground and the back and arm supported, and with the antecubital fossa at the level of the heart. The maximum cuff inflation was calculated by adding $30 \mathrm{mmHg}$ to the pulse obliteration pressure, and the cuff was deflated at a constant rate of 2 to $4 \mathrm{mmHg}$ per second. Venous blood was collected in the morning after overnight fasting, serum samples were stored at $4{ }^{\circ} \mathrm{C}$ and were subject to testing (Hitachi $7170 \mathrm{~s}$ autoanalyzer) within 2 days, according to the instruction of analyzer, fasting blood glucose (FBG), triglycerides (TG), and high density lipoprotein cholesterol (HDL), cholesterol, uric acid, serum creatinine (Scr) were measured by enzymatic method using fullautomatic biochemical analyser (Hitachi 7170 s). Estimated glomerular filtration rate $[25]=186 \times \mathrm{Scr}^{-1.154} \times$ age $^{-0.203} \times 0.742$ [if female].

All the participants' morning urine specimens were tested. Urinary microalbumin was measured using the ELISA method. MAU $<20 \mathrm{mg} / \mathrm{L}$ was defined as normoalbuminuria, while $\geq 20 \mathrm{mg} / \mathrm{L}$ was defined as high MAU [26].

Brachial-ankle artery pulse wave velocity (baPWV) was used to evaluate arterial stiffness. After a 5-min rest in a supine position, baPWV was measured using the ColinVP1000 (Omron, Japan) by trained nurses between 7 AM and 9 AM, with monitoring cuffs placed around both the upper and lower extremities, the data were recorded simultaneously by the instrument [27]. The time interval between the wave front of brachial waveform and that of ankle waveform was defined as the time interval between brachium and ankle $(\Delta \mathrm{Tba})$. The path length from the heart to the brachium (Lb) was expressed using the following equation: $\mathrm{Lb}=0.2195 \times$ height of the patient $(\mathrm{cm})-2.0734$. The path length from the heart to ankle (La) was expressed using the following equation: $\mathrm{La}=(0.8129 \times$ height of the patient $(\mathrm{cm})+12.328)$. The baPWV was then calculated as follows: baPWV $=(\mathrm{La} / \mathrm{Lb}) / \mathrm{Tba}$. baPWV $\geq 1400 \mathrm{~cm} / \mathrm{s}$ was considered high arterial stiffness [28].

\section{Definition of MetS and grouping}

Definition of MetS is in accordance with the International Diabetes Federation/National Heart, Lung and Blood Institute/American Heart Association (IDF/NHLBI/AHA2009) criteria, which are based on the presence of at least three of five risk factors (central obesity, elevated serum TG, low HDL, elevated BP, and elevated FBG). The cut-off values were as follows: 1) Central obesity, defined for Asian populations as $\mathrm{WC} \geq 90 \mathrm{~cm}$ for males and $\mathrm{WC} \geq 80 \mathrm{~cm}$ for females; 2) Elevated serum TG, defined as $>1.7 \mathrm{mmol} / \mathrm{L}$; 3) Low HDL, defined as $<1.0 \mathrm{mmol} / \mathrm{L}$ for males and $<1.3 \mathrm{mmol} / \mathrm{L}$ for females; 4) Elevated BP, defined as systolic blood pressure (SBP) $\geq 130$ or diastolic blood pressur$\mathrm{e}(\mathrm{DBP}) \geq 85 \mathrm{mmHg}$ or current use of anti-hypertensive medication; and 5) Elevated FBG, defined as $\geq 5.6 \mathrm{mmol} / \mathrm{L}$ or the current use of anti-diabetic medication. 
Because MetS is defined by the presence of three or more altered components, participants with MetS have different combinations of the individual components of MetS (we abbreviated BP, FBG, WC, TG, HDL-c as B, G, W, T, H), such as WHT, BGWT, BGWTH.

All of the participants were divided into four groups according to the different combinations of MAU and baPWV values: 1) $\mathrm{MAU}(-) / \mathrm{iAS}(-)$ : $\mathrm{baPWV}<1400 \mathrm{~cm} / \mathrm{s}$ and $\mathrm{MAU}<20 \mathrm{mg} / \mathrm{L} ; 2) \mathrm{MAU}(+) / \mathrm{iAS}(-): \mathrm{MAU} \geq 20 \mathrm{mg} / \mathrm{L}$ and baPWV $<1400 \mathrm{~cm} / \mathrm{s}$; 3) MAU(-)/iAS(+): baPWV $\geq 1400 \mathrm{~cm} / \mathrm{s}$ and $\mathrm{MAU}<20 \mathrm{mg} / \mathrm{L}$; 4) $\mathrm{MAU}(+) / \mathrm{iAS}(+): \mathrm{baPWV} \geq 1400 \mathrm{~cm} / \mathrm{s}$ and $M A U \geq 20 \mathrm{mg} / \mathrm{L}$.

\section{Statistical analysis}

SPSS 22.0 was applied. Continuous variables are expressed as mean \pm standard deviation or interquartile range according to the distribution. Categorical variables are presented as percentages. Continuous variables between four groups were compared using one-way ANOVA or Kruskal-Wallis test, and categorical variables were compared using the $\mathrm{X}^{2}$ test. Multinomial logistic regression models (MLRM) for age, gender, uric acid, smoking status (never, former or current) and history of cardiovascular diseases (cerebrovascular events, coronary disease, peripheral arterial disease) and total cholesterol adjustment were used to explore the odds ratios of $\mathrm{MAU}(-) / \mathrm{iAS}(+), \mathrm{MAU}(+) / \mathrm{iAS}(-), \mathrm{MAU}(+) / \mathrm{iAS}(+)$ based on MetS-related risk factors, including: 1) MetS itself, 2) The number of positive MetS components, 3) Individual MetS components, and 4) The clusters of MetS components. MAU(-)/iAS(-) was used as a reference. $P<0.05$ was considered significant.

\section{Results}

Characteristics of the participants and prevalence of MetS components in the MAU(-)/iAS(-), MAU(+)/iAS(-), MAU(-)/iAS(+), MAU(+)/iAS(+) groups

The clinical characteristics of 11,911 participants $(52 \pm$ 5.6 years) in this study are shown in Table 1.The prevalence of $\mathrm{MAU}(-) / \mathrm{iAS}(-), \mathrm{MAU}(+) / \mathrm{iAS}(-), \mathrm{MAU}(-) /$ iAS(+), MAU(+)/iAS(+) was $35 \%, 15 \%, 27 \%$, and $23 \%$. The proportions of elevated BP, FBG, WC, and TG were the highest, and the proportion of decreased HDL-c was the second highest in the $\mathrm{MAU}(+) / \mathrm{iAS}(+)$ group; all of these parameters were proportionally the lowest in the MAU(-)/ iAS(-) group. Compared with $\mathrm{MAU}(+) / \mathrm{iAS}(-)$, the MAU(-)/iAS(+) group had higher proportion of elevated FBG, TG, BP and lower proportion of decreased HDL-c, whereas the proportions of elevated WC were equal in the $\mathrm{MAU}(+) / \mathrm{iAS}(-)$ and $\mathrm{MAU}(-) / \mathrm{iAS}(+)$ groups (Fig. 1).

\section{Components of MetS associated with MAU/iAS comorbidity}

Table 2 refers to MAU(-)/iAS(-) as the reference group. Only elevated BP, FBG, and TG displayed the strongest associations with $\mathrm{MAU}(+) / \mathrm{iAS}(+)$, the $\mathrm{MAU}(+) / \mathrm{iAS}(-)$ group was associated with WC whereas $\mathrm{MAU}(-) / \mathrm{iAS}(+)$ was not associated. There were higher risk of having elevated $\mathrm{BP}(\mathrm{OR}=4.83, P<0.01$ vs. $1.62, P<0.01)$ and TG $(\mathrm{OR}=1.37, P<0.01$ vs. $1.20, P<0.05)$ in $\mathrm{MAU}(-) /$ $\mathrm{iAS}(+)$ compared with the risk in $\mathrm{MAU}(+) / \mathrm{iAS}(-)$, conversely, lower risk of elevated FBG $(\mathrm{OR}=1.31, P<0.01$ vs. 1.37, $P<0.01)$ in $\mathrm{MAU}(-) / \mathrm{iAS}(+)$. Decreased HDL-c (OR $=1.84, P<0.01$ vs. $1.21, P<0.05$ and $1.49, P<0.01$ ) was the most strongly associated with $\mathrm{MAU}(+) / \mathrm{iAS}(-)$ compared with $\mathrm{MAU}(-) / \mathrm{iAS}(+)$ and $\mathrm{MAU}(+) / \mathrm{iAS}(+)$ (Table 2$)$.

\section{Number of MetS components associated with MAU/iAS comorbidity}

A positive effect of MetS on the presence of MAU(+)/ $\mathrm{iAS}(-), \operatorname{MAU}(-) / \mathrm{iAS}(+)$, or MAU(+)/iAS(+) is listed in ascending order based on odds ratios $(\mathrm{OR}=2.11,2.41,4.61$, respectively; $P<0.01$ ). The ascending OR trend could also be observed when analyzing the influence of an increasing number of positive MetS components on MAU(+)/iAS(-), MAU(-)/iAS(+), and MAU(+)/iAS(+) (Table 3).

\section{Clusters of MetS components associated with MAU/iAS comorbidity}

The frequency of the clusters (GHT, GWH, BWH, BGH, GWTH, BGWH) was low (less than 1\%); therefore, we combined these clusters into an "other" category. Compared with the individuals without MetS, those with the BGTH cluster had the greatest likelihood of presenting a MAU(-)/iAS(+) $(\mathrm{OR}=5.98, P<0.01)$ or $\mathrm{MAU}(+) / \mathrm{iAS}(+)$ $(\mathrm{OR}=13.17, P<0.01)$ profile; this likelihood was even greater than that associated simultaneous alteration in all five MetS components(BGWTH) $(\mathrm{MAU}(-) / \mathrm{iAS}(+)$ :OR = 3.89, $P<0.01 ; \mathrm{MAU}(+) / \mathrm{iAS}(+)$ :OR $=10.77, P<0.01)$. As the third most influential cluster for MAU(-)/iAS(+) and $\mathrm{MAU}(+) / \mathrm{iAS}(+)$, the odds ratio for patients with BWG (MAU(-)/iAS(+): $\mathrm{OR}=3.63, \quad P<0.01 ; \quad \mathrm{MAU}(+) / \mathrm{iAS}(+)$ : $\mathrm{OR}=8,37, P<0.01)$ was greater than that for patients with most of the clusters with four altered components. Regarding $\mathrm{MAU}(+) / \mathrm{iAS}(-)$, the most influential clusters were BGWTH $(\mathrm{OR}=5.22, P<0.01)$, GWTH $(\mathrm{OR}=4.08$, $P<0.01)$ and $\mathrm{BGW}(\mathrm{OR}=3.40, P<0.01)$, which are listed in descending order of ORs. WTH $(\mathrm{OR}=2.45, P<0.01)$, WGT $(\mathrm{OR}=1.49, P<0.05)$ and $\mathrm{GWTH}(\mathrm{OR}=4.08$, $P<0.01)$ were associated with $\mathrm{MAU}(+) / \mathrm{iAS}(-)$ but not with $\mathrm{MAU}(-) / \mathrm{iAS}(+)$, whereas $\mathrm{BTH}$ was only associated with $\mathrm{MAU}(-) / \mathrm{iAS}(+)(\mathrm{OR}=2.97, P<0.01)$ and $\mathrm{MAU}(+) /$ iAS $(+)(\mathrm{OR}=3.27, P<0.01)($ Table 4$)$.

\section{Discussion}

This current study has shown the heterogeneous association between cross-combination of MAU/iAS and MetS itself, the number of positive MetS components, individual MetS components, the clusters of MetS components. 
Table 1 Characteristic of participants

\begin{tabular}{|c|c|c|c|c|c|c|}
\hline Variables & $\begin{array}{l}\text { Total } \\
N=11,911\end{array}$ & $\begin{array}{l}\mathrm{MA}(-) / \mathrm{AS}(-) \\
N=4228\end{array}$ & $\begin{array}{l}\mathrm{MA}(+) / \mathrm{AS}(-) \\
N=1714\end{array}$ & $\begin{array}{l}\mathrm{MA}(-) / \mathrm{AS}(+) \\
N=3238\end{array}$ & $\begin{array}{l}\mathrm{MA}(+) / \mathrm{AS}(+) \\
N=2731\end{array}$ & $P$ \\
\hline Age (years) & $52 \pm 5.6$ & $50 \pm 4.7$ & $50 \pm 4.6$ & $54 \pm 5.8$ & $53 \pm 5.9$ & 0.000 \\
\hline Male & 8105 (68.0\%) & 2610 (61.7\%) & $1320(77.0 \%)$ & 2078 (64.2\%) & 2097 (76.8\%) & 0.000 \\
\hline $\mathrm{SBP}(\mathrm{mmHg})$ & $128 \pm 17.2$ & $118 \pm 12.5$ & $121 \pm 13.1$ & $134 \pm 16.0$ & $139 \pm 17.4$ & 0.000 \\
\hline $\mathrm{DBP}(\mathrm{mmHg})$ & $81 \pm 12.0$ & $76 \pm 9.8$ & $79 \pm 10.3$ & $85 \pm 11.1$ & $89 \pm 12.3$ & 0.000 \\
\hline WC (cm) & $86 \pm 8.8$ & $84 \pm 9.9$ & $86 \pm 9.0$ & $85 \pm 8.3$ & $88 \pm 8.4$ & 0.000 \\
\hline FBG (mmol/L) & $5.2(4.8,5.8)$ & $5.1(4.8,5.5)$ & $5.1(4.8,5.7)$ & $5.3(4.9,5.8)$ & $5.5(5.0,6.4)$ & 0.000 \\
\hline TG $(\mathrm{mmol} / \mathrm{L})$ & $1.5(1.1 .2 .3)$ & $1.4(1.0,1.9)$ & $1.6(1.1,2.3)$ & $1.6(1.1,2.3)$ & $1.8(1.2,2.7)$ & 0.000 \\
\hline $\mathrm{HDL}(\mathrm{mmol} / \mathrm{L})$ & $1.5 \pm 0.4$ & $1.5 \pm 0.4$ & $1.4 \pm 0.4$ & $1.5 \pm 0.4$ & $1.4 \pm 0.4$ & 0.000 \\
\hline $\begin{array}{l}\text { Cholesterol } \\
(\mathrm{mmol} / \mathrm{L})\end{array}$ & $5.3 \pm 1.0$ & $5.2 \pm 0.9$ & $5.1 \pm 1.0$ & $5.3 \pm 1.0$ & $5.3 \pm 1.1$ & 0.000 \\
\hline $\begin{array}{l}\text { Uric acid } \\
(\mathrm{mmol} / \mathrm{L})\end{array}$ & $320 \pm 92$ & $304 \pm 90$ & $325 \pm 88$ & $321 \pm 92$ & $340 \pm 95$ & 0.000 \\
\hline Non-smoker & 6606 (55.5\%) & 2529 (59.8\%) & 833 (48.6\%) & 1901 (58.7\%) & 1343 (49.2\%) & 0.000 \\
\hline $\begin{array}{l}\text { Antihyper- } \\
\text { tensive }\end{array}$ & $557(4.7 \%)$ & $162(3.8 \%)$ & 142 (8.3\%) & $135(4.2 \%)$ & 118 (4.3\%) & 0.000 \\
\hline Antidiabetic & $365(3.1 \%)$ & $55(1.3 \%)$ & $45(2.6 \%)$ & 107 (3.3\%) & 158 (5.8\%) & 0.000 \\
\hline History of CVD & $221(1.9 \%)$ & $42(1.0 \%)$ & $22(1.3 \%)$ & 74 (2.3\%) & $83(3.0 \%)$ & 0.000 \\
\hline
\end{tabular}

Compared between four groups. Data was presented as proportion rate $\%$, median (interquartile range) or mean \pm standard deviation

There are close relation between iAS or MAU to the prediction and development of cardiovascular diseases $[29,30]$. The influence of MetS on arterial stiffness or MAU has clearly been demonstrated [31-33]. The novelty of our study is that we combined the study of iAS and MAU, which both reflect vascular organ damage, and found that MetS-related risk factors heterogeneously contributed to phenotypes of vascular damage to different body parts. To reduce the influence of age, which is an essential factor in vascular aging, we chose

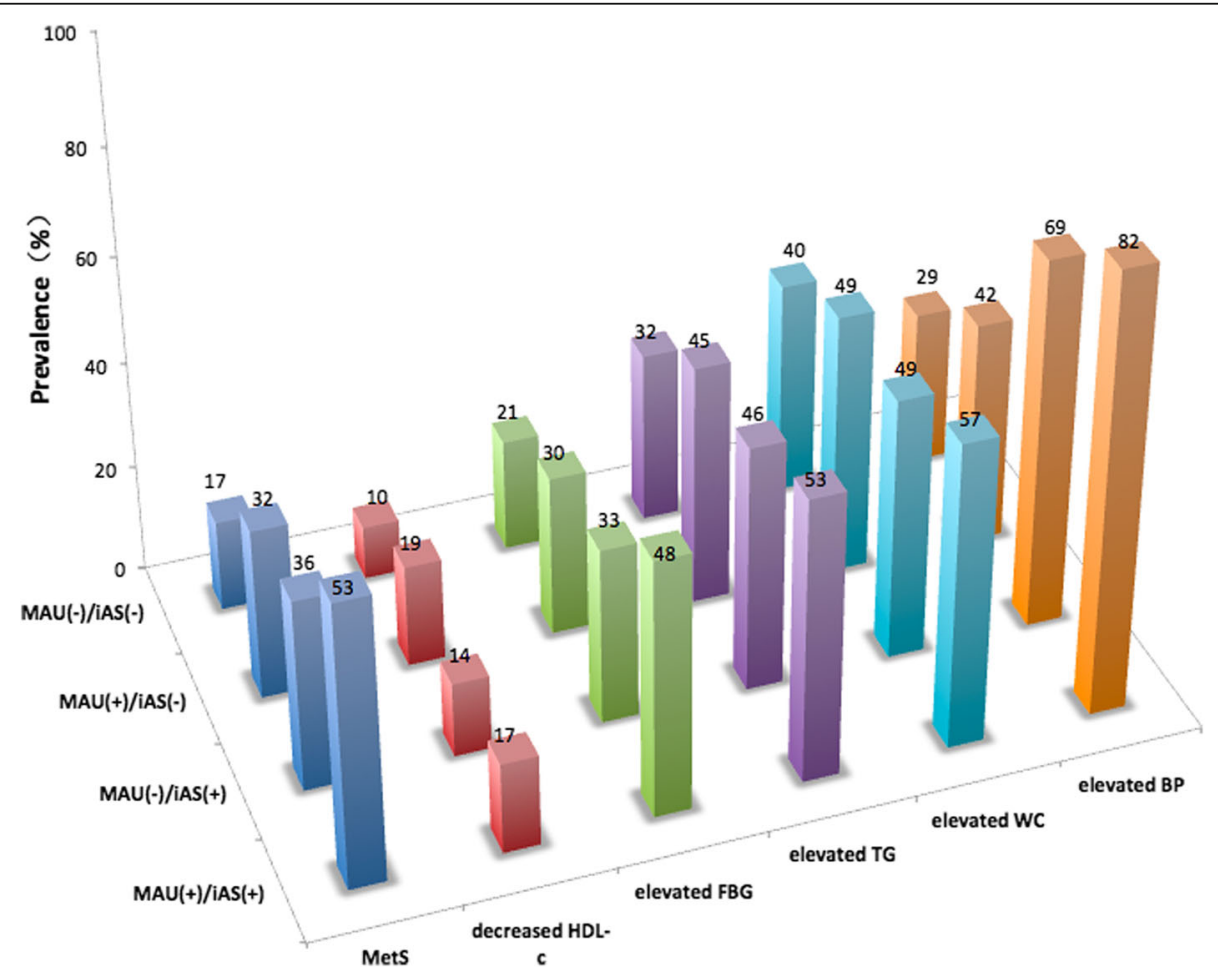

Fig. 1 The prevalence of MetS components in the MAU(-)/iAS(-), MAU(+)/iAS(-), MAU(-)/iAS(+), and MAU(+)/iAS(+) groups 
Table 2 Association between MetS components and different comorbidities of iAS and MAU

\begin{tabular}{|c|c|c|c|c|c|c|c|}
\hline \multirow[t]{2}{*}{ Variables } & \multirow{2}{*}{$\begin{array}{l}\text { MAU(-)/iAS(-) } \\
\text { OR }\end{array}$} & \multicolumn{2}{|c|}{ MAU(+)/iAS(-) } & \multicolumn{2}{|c|}{ MAU(-)/iAS(+) } & \multicolumn{2}{|c|}{$\operatorname{MAU}(+) / \mathrm{iAS}(+)$} \\
\hline & & OR & $95 \% \mathrm{Cl}$ & OR & $95 \% \mathrm{Cl}$ & OR & $95 \% \mathrm{Cl}$ \\
\hline Elevated BP & 1.0 & $1.62^{* *}$ & $1.43-1.83$ & $4.83^{* *}$ & $4.35-5.37$ & $8.67^{* *}$ & $7.66-9.81$ \\
\hline Elevated FBG & 1.0 & $1.37^{* *}$ & $1.20-1.57$ & $1.31^{* *}$ & $1.17-1.48$ & $2.40^{* *}$ & $2.13-2.71$ \\
\hline Elevated WC & 1.0 & $1.28^{* *}$ & $1.13-1.44$ & 0.98 & $0.88-1.09$ & $1.24^{* *}$ & $1.10-1.39$ \\
\hline Elevated TG & 1.0 & $1.20^{*}$ & $1.04-1.39$ & $1.37^{* *}$ & $1.21-1.56$ & $1.41^{* *}$ & $1.24-1.62$ \\
\hline Decreased HDL-C & 1.0 & $1.84^{* *}$ & $1.54-2.19$ & $1.21^{*}$ & $1.02-1.43$ & $1.49^{* *}$ & $1.26-1.77$ \\
\hline
\end{tabular}

to examine a middle-aged population [34]. We used MLRM instead of the standard logistic regression model (SLRM), which requires that MAU and arterial stiffness be considered separately as dependent variables; however, a limitation of the SLRM its the lower efficacy. For instance, when the predictors of MAU were analyzed, the reference category (i.e., no increase in MAU) consisted of individuals who may suffer from iAS; this may have resulted in a confounding bias in the estimation of risk factors' effects on MAU because high MAU and iAS might share similar risk factors. The same principle applied to the analysis of risk factors of arterial stiffness. Furthermore, the MLRM is more sophisticated, allowing the simultaneous estimation of the risk factors' effects on both the presence of and the association between MAU and iAS without bias arising from the nonindependence of the outcomes [35].

Consistant with our hypothesis that iAS and MAU may represent a continuum in some populations with more severe vascular while individuals with less severe vascular disease express only MAU or iAS, high microalbuminuria and arterial stiffness coexistd in a substantial percentage of individuals who exposed to relatively higher degree of MetS, which suggested increased propensity towards worse vascular condition [36].

Previous studies have reported that an increasing number of MetS components has an increasingly negative effect on iAS [37] or MAU [38]. According to MLRM, the overall risk of having MAU alone was lower than that of having iAS alone with regard to the effect of metabolic disturbances, regardless of the number of MetS components or the presence of MetS. When analyzing individual components, we found that elevated BP was the main distinguishing factor, contributing to a much higher risk of arterial stiffness alone. The ORs for the risk of elevated BP associated with baPWV in a Chinese population were between 5.4 (OR for males) and 12.6 (OR for females) [39]. The risks of having high baPWV with or without MAU in our results were within or below this range and more accurately revealed the different associations between blood pressure and arterial stiffness in the presence of confounding factors. Our research revealed that abdominal obesity was not associated with baPWV alone. Studies have reported a negative association between obesity and vascular stiffness in young people $[40,41]$, but a positive association was reported in older adults and the elderly [42]. The physiological mechanisms linking body fat with arterial stiffness are not fully understood; however, we speculated that with increases in age, body fat becomes increasingly more positively associated with PWV [43], and middle age is a turning point. Mechanism of MetS-related arterial stiffness and microalbuminuria elevation involves oxidative, nitrosative stress [44, 45], and inflammation [46], for example, via these products, hyperglycemia increases endothelial [47] and glomerular filtration barrier permeability [48], and accelerates arterial stiffness [49],

Table 3 Association between MetS or the number of positive MetS components and different comorbidities of MAU and iAS

\begin{tabular}{|c|c|c|c|c|c|c|c|}
\hline \multirow[t]{2}{*}{ Variables } & \multirow{2}{*}{$\begin{array}{l}\mathrm{MA}(-) / \mathrm{AS}(-) \\
\mathrm{OR}\end{array}$} & \multicolumn{2}{|c|}{$\mathrm{MA}(+) / \mathrm{AS}(-)$} & \multicolumn{2}{|c|}{$\mathrm{MA}(-) / \mathrm{AS}(+)$} & \multicolumn{2}{|c|}{$\mathrm{MA}(+) / \mathrm{AS}(+)$} \\
\hline & & $\mathrm{OR}$ & $95 \% \mathrm{Cl}$ & OR & $95 \% \mathrm{Cl}$ & OR & $95 \% \mathrm{Cl}$ \\
\hline MetS & 1.0 & $2.11^{* *}$ & $1.84-2.41$ & $2.41^{* *}$ & $2.16-2.71$ & $4.61^{* *}$ & $4.11-5.18$ \\
\hline \multicolumn{8}{|c|}{ Num. of MetS } \\
\hline \multicolumn{8}{|l|}{0 (ref) } \\
\hline 1 & 1.0 & 1.17 & $0.99-1.39$ & $2.13^{* *}$ & $1.81-2.50$ & $3.25^{* *}$ & $2.59-4.10$ \\
\hline 2 & 1.0 & $1.65^{* *}$ & $1.38-1.96$ & $3.98^{* *}$ & $3.38-4.69$ & $8.39^{* *}$ & $6.69-10.52$ \\
\hline 3 & 1.0 & $2.33^{* *}$ & $1.92-2.83$ & $4.99^{* *}$ & $4.87-5.98$ & $15.85^{* *}$ & $12.54-20.02$ \\
\hline 4 & 1.0 & $4.05^{* *}$ & $3.14-5.22$ & $7.35^{* *}$ & $5.81-9.29$ & $30.39^{* *}$ & $23.10-39.98$ \\
\hline 5 & 1.0 & $6.16^{* *}$ & $3.69-10.14$ & $9.64^{* *}$ & $6.06-15.33$ & $46.65^{* *}$ & $29.14-74.70$ \\
\hline
\end{tabular}


Table 4 Association between MetS clusters and different comorbidities of MAU and iAS

\begin{tabular}{|c|c|c|c|c|c|c|c|c|}
\hline \multirow[b]{2}{*}{ Variables } & \multirow{2}{*}{$\begin{array}{l}\text { Prevalence } \\
\text { (n) }\end{array}$} & \multirow{2}{*}{$\begin{array}{l}\text { MAU(-)/iAS(-) } \\
\text { OR }\end{array}$} & \multicolumn{2}{|c|}{$\mathrm{MAU}(+) / \mathrm{iAS}(-)$} & \multicolumn{2}{|c|}{ MAU(-)/iAS(+) } & \multicolumn{2}{|c|}{$\mathrm{MAU}(+) / \mathrm{iAS}(+)$} \\
\hline & & & OR & $95 \% \mathrm{Cl}$ & OR & $95 \% \mathrm{Cl}$ & OR & $95 \% \mathrm{Cl}$ \\
\hline$\overline{\text { WTH }}$ & 158 & 1 & $2.45^{* *}$ & $1.68-3.59$ & 0.77 & $0.48-1.23$ & 0.65 & $0.36-1.17$ \\
\hline WGT & 290 & 1 & $1.49^{*}$ & $1.06-2.10$ & 0.98 & $0.71-1.34$ & 1.25 & $0.88-1.76$ \\
\hline BTH & 129 & 1 & 1.42 & $0.72-2.78$ & $2.97^{* *}$ & $1.83-4.81$ & $3.27^{* *}$ & $1.95-5.48$ \\
\hline BWT & 800 & 1 & $1.67^{* *}$ & $1.28-2.19$ & $2.28^{* *}$ & $1.84-2.82$ & $3.79^{* *}$ & $3.05-4.70$ \\
\hline BGT & 337 & 1 & $1.72^{*}$ & $1.05-2.82$ & $3.13^{* *}$ & $2.18-4.50$ & $7.82^{* *}$ & $5.52-11.08$ \\
\hline BWG & 507 & 1 & $2.65^{* *}$ & $1.82-3.87$ & $3.63^{* *}$ & $2.67-4.93$ & $8.37^{*}$ & $6.20-11.29$ \\
\hline GWTH & 112 & 1 & $4.08^{* *}$ & $2.44-6.83$ & 1.54 & $0.89-2.64$ & $2.08^{*}$ & $1.16-3.74$ \\
\hline BWTH & 226 & 1 & $2.87^{* *}$ & $1.81-4.57$ & $2.98^{* *}$ & $2.00-4.44$ & $4.95^{* *}$ & $3.32-7.43$ \\
\hline BGTH & 115 & 1 & $2.74^{*}$ & $1.11-6.80$ & $5.98^{* *}$ & $2.95-12.14$ & $13.17^{* *}$ & $6.59-26.32$ \\
\hline BGWT & 714 & 1 & $3.40^{* *}$ & $2.49-4.64$ & $2.94^{* *}$ & $2.24-3.86$ & $8.20^{* *}$ & $6.31-10.64$ \\
\hline BGWTH & 263 & 1 & $5.22^{* *}$ & $3.18-8.57$ & $3.89^{* *}$ & $2.48-6.11$ & $10.77^{* *}$ & $6.97-16.63$ \\
\hline Others & 270 & 1 & $2.40^{* *}$ & $1.59-3.63$ & $2.28^{* *}$ & $1.57-3.31$ & $5.02^{* *}$ & $3.53-7.15$ \\
\hline
\end{tabular}

W: increased waist circumference, $\mathrm{T}$ : increased triglycerides, B: increased blood pressure, G: increased fasting blood glucose, $\mathrm{H}$ : decreased $\mathrm{HDL}-\mathrm{c} .{ }^{*} P<0.05,{ }^{* *} P<0.01$

inversely, antioxidant effects of HDL-c contributes to the vascular protection [50].

Previous studies examined the clusters of altered MetS components associated with the burden of large arteries $[12,51]$, while the current study reported the simultaneous impact of specific MetS clusters on the heterogeneity of phenotypes of macro- and microvascular abnormalities. The clusters identified as the three most significant determinants of stiff arteries alone and comorbid stiff arteries and microalbuminuria were similar but differed from the determinants of microalbuminuria alone. Moreover, containing B and G was necessary for the clusters to positively impact iAS and MAU, respectively. In light of this disparity, it was possible for us to predict macro- or microvascular complications according to the different predictive powers of specific MetS clusters and to provide specific follow up for patients who are susceptible to these predicted vascular diseases.

The first limitation of our study was that we report analysis from cross-sectional data only. Therefore, we cannot conclude about the role of MetS-related risk factors as potential predictiors of future events (nor was this a goal of the present study). Secondly, baPWV has been criticized to span a more heterogeneous arterial tree than carotidfemoral pulse wave velocity (cfPWV), thus subsumes greater heterogeneity, cfPWV has been more accurate and reliable [52, 53], however, as the target arteries may be somewhat difficult to be perceived by probes, the utilization of this cfPWV is lower than baPWV [53]. Since there was a strong positive association between cfPWV and baPWV [54], we assume that the result is also reliable.

This observational study suggested that MetS itself, the number of positive MetS components, individual MetS components, and the clusters of MetS components showed different patterns of associations with MAU or
iAS. According to this study, we present the specifically protective pathway of vascular complication, for example, microvascular impairment rather than macrovascular stiffness should be more closely monitored in people with combination of elevated WC, TG, blood pressure. In summary, these heterogeneous influences of MetS-related risk factors suggest possible preventive intervention: identifying, assessing, and following up more selectively individuals with specific metabolic disturbance may facilitate effective prevention of types of vascular injuries.

\section{Conclusion}

Heterogeneous association exist between MetS and cross-combination of MAU/iAS, based on these heterogeneous influences of MetS-related risk factors on MAU and iAS, identifying different types of vascular injuries could be selectively targeted.

\section{Abbreviations}

baPW: Brachial-ankle artery pulse wave velocity; BP: Blood pressure; FBG: fasting blood glucose; HDL: high density lipoprotein cholesterol; iAS: Increased arterial stiffness; MAU: microalbuminuria; MetS: metabolic syndrome; MLRM: Multinomial logistic regression models; SLRM: standard logistic regression model; TG: triglycerides; WC: waist circumference

\section{Funding}

The work was supported by National Natural Science Foundation of China (81600357) and the New Xiangya Talent Project of the Third Xiangya hospital of Central South University (JY201714).

Availability of data and materials

The raw data is available from the corresponding author upon reasonable request.

Authors' contributions

HC made substantial contributions to conception and design. RM was involved in drafting the manuscript and revising it critically for important intellectual content, LW was involved in drafting the manuscript and revision. PN analysised and interpretated the data. YZ contributed in acquisition of data. All authors read and approved the final manuscript. 


\section{Ethics approval and consent to participate}

This study was conducted according to the principles expressed in the Declaration of Helsinki and was approved by the Ethics Committee of the Third Xiangya Hospital, and the consent form was signed by each participant.

\section{Competing interests}

The authors declare that they have no competing interests.

\section{Publisher's Note}

Springer Nature remains neutral with regard to jurisdictional claims in published maps and institutional affiliations.

\section{Author details}

'Department of Health Management, the Third Xiangya Hospital, Central South University, Tongzipo Road 138, Changsha 410013, Hunan Province, China. ${ }^{2}$ Institute of Aviation Medicine, Beijing, China. ${ }^{3}$ Statistics Department, Public Health Academy, Central South University, Changsha, Hunan, China.

\section{Received: 12 April 2017 Accepted: 24 April 2018}

\section{Published online: 04 May 2018}

\section{References}

1. Pietri P, Vlachopoulos C, Vyssoulis G, loakeimidis N, Stefanadis C. Macro- and microvascular alterations in patients with metabolic syndrome: sugar makes the difference. Hypertens Res. 2014;37(5):452-6.

2. Abdelhafiz AH, Ahmed S, El Nahas M. Microalbuminuria: marker or maker of cardiovascular disease. Nephron Exp Nephrol. 2011;119(Suppl 1):e6-10.

3. Shirwany NA, Zou MH. Arterial stiffness: a brief review. Acta Pharmacol Sin. 2010;31(10):1267-76

4. Wen W, Luo R, Tang X, Tang L, Huang HX, Wen X, et al. Age-related progression of arterial stiffness and its elevated positive association with blood pressure in healthy people. Atherosclerosis. 2015;238(1):147-52.

5. Yun YW, Shin MH, Lee YH, Rhee JA, Choi JS. Arterial stiffness is associated with diabetic retinopathy in Korean type 2 diabetic patients. J Prev Med Public Health. 2011;44(6):260-6.

6. de Zeeuw D, Parving HH, Henning RH. Microalbuminuria as an early marker for cardiovascular disease. J Am Soc Nephrol. 2006;17(8):2100-5.

7. Bjornstad P, Maahs DM. Diabetes complications in childhood diabetes-new biomarkers and technologies. Curr Pediatr Rep. 2015;3(2):177-86.

8. Shin DI, Seung KB, Yoon HE, Hwang BH, Seo SM, Shin SJ, et al. Microalbuminuria is independently associated with arterial stiffness and vascular inflammation but not with carotid intima-media thickness in patients with newly diagnosed type 2 diabetes or essential hypertension. J Korean Med Sci. 2013;28(2):252-60.

9. Seo JY, Kim MK, Choi BY, Kim YM, Cho SI, Shin J. Elevated brachial-ankle pulse wave velocity is independently associated with microalbuminuria in a rural population. J Korean Med Sci. 2014;29(7):941-9.

10. Kim BJ, Lee HA, Kim NH, Kim MW, Kim BS, Kang JH. The association of albuminuria, arterial stiffness, and blood pressure status in nondiabetic, nonhypertensive individuals. J Hypertens. 2011;29(11):2091-8.

11. Munakata M, Miura Y, Yoshinaga K. Group JTs. Higher brachial-ankle pulse wave velocity as an independent risk factor for future microalbuminuria in patients with essential hypertension: the J-TOPP study. J Hypertens. 2009; 27(7):1466-71.

12. Scuteri A, Cunha PG, Rosei EA, Badariere J, Bekaert S, Cockcroft JR, et al. Arterial stiffness and influences of the metabolic syndrome: a crosscountries study. Atherosclerosis. 2014;233(2):654-60.

13. Lee HO, Bak HJ, Shin JY, Song YM. Association between metabolic syndrome and microalbuminuria in Korean adults. Korean J Fam Med. 2015; 36(2):60-71

14. Kuang DW, Li CL, Kuok UI, Cheung K, Lio WI, Xin J. Risk factors associated with brachial-ankle pulse wave velocity among peritoneal dialysis patients in Macao. BMC Nephrol. 2012;13:143.

15. Chen F, Yang W, Weng J, Jia W, Ji L, Xiao J, et al. Albuminuria: prevalence, associated risk factors and relationship with cardiovascular disease. J Diabetes Investig. 2014:5(4):464-71.

16. Diaz A, Tringler M, Galli C, Ramirez A, Fischer El. Arterial stiffness in a rural population of Argentina: pilot study. High Blood Press Cardiovasc Prev. 2015;22(4):403-9.
17. Zacharias JM, Young TK, Riediger ND, Roulette J, Bruce SG. Prevalence, risk factors and awareness of albuminuria on a Canadian first nation: a community-based screening study. BMC Public Health. 2012;12:290.

18. Jang SY, Ju EY, Huh EH, Kim JH, Kim DK. Determinants of brachial-ankle pulse wave velocity and carotid-femoral pulse wave velocity in healthy Koreans. J Korean Med Sci. 2014;29(6):798-804.

19. Xu L, Jiang CQ, Lam TH, Cheng KK, Yue XJ, Lin JM, et al. Impact of impaired fasting glucose and impaired glucose tolerance on arterial stiffness in an older Chinese population: the Guangzhou biobank cohort study-CVD. Metabolism. 2010;59(3):367-72.

20. Munakata M, Konno S, Ohshima M, Ikeda T, Miura Y, Ito S. High-normal blood pressure is associated with microalbuminuria in the general population: the Watari study. Hypertens Res. 2011;34(10):1135-40.

21. Rim JH, Lee YH, Cha BS, Lee SG, Kim JH. Central obesity is an independent risk factor for microalbuminuria in both the general Korean women and nondiabetic nonhypertensive subpopulation: association of microalbuminuria and metabolic syndrome from the Korea National Health and nutrition examination survey 2011-2012. Clin Chim Acta. 2015;448:74-9.

22. Mikhed Y, Daiber A, Steven S. Mitochondrial oxidative stress, mitochondrial DNA damage and their role in age-related vascular dysfunction. Int J Mol Sci. 2015;16(7):15918-53.

23. Organization WH. Measuring obesity - classification and description of anthropometric data: report on a WHO consultation on the epidemiology of obesity. Warsaw. 1987:2.

24. Pickering TG, Hall JE, Appel LJ, Falkner BE, Graves J, Hill MN, et al. Recommendations for blood pressure measurement in humans and experimental animals: part 1: blood pressure measurement in humans: a statement for professionals from the Subcommittee of Professional and Public Education of the American Heart Association Council on high blood pressure research. Circulation. 2005;111(5):697-716.

25. Levey ASGT, Kusek JW, et al. A simplified equation to predict glomerular filtration rate from serum creatinine. J Am Soc Nephrol. 2000;11:828.

26. van der Tol A, Van Biesen W, Van Laecke S, Bogaerts K, De Lombaert K, Warrinnier $\mathrm{H}$, et al. Statin use and the presence of microalbuminuria. Results from the ERICABEL trial: a non-interventional epidemiological cohort study. PLoS One. 2012:7(2):e31639.

27. Tomiyama H, Yamashina A, Arai T, Hirose K, Koji Y, Chikamori T, et al. Influences of age and gender on results of noninvasive brachial-ankle pulse wave velocity measurement-a survey of 12517 subjects. Atherosclerosis. 2003;166(2):303-9.

28. Wang A, Tao J, Guo X, Liu X, Luo Y, Liu X, et al. The product of resting heart rate times blood pressure is associated with high brachial-ankle pulse wave velocity. PLoS One. 2014;9(9):e107852.

29. Sakuragi S, Abhayaratna WP. Arterial stiffness: methods of measurement, physiologic determinants and prediction of cardiovascular outcomes. Int J Cardiol. 2010;138(2):112-8.

30. Khoshdel AR, Carney SL, Gillies A. Circulatory syndrome: an evolution of the metabolic syndrome concept! Curr Cardiol Rev. 2012;8(1):68-76.

31. Anvari MS, Boroumand MA, Pourgholi L, Sheikhfathollahi M, Rouhzendeh M, Rabbani S, et al. Potential link of microalbuminuria with metabolic syndrome in patients undergoing coronary angiography. Arch Med Res. 2009;40(5):399-405.

32. Vyssoulis G, Karpanou E, Spanos P, Kyvelou SM, Adamopoulos D, Stefanadis C. Urine albumin excretion, within normal range, reflects increasing prevalence of metabolic syndrome in patients with essential hypertension. J Clin Hypertens (Greenwich). 2010;12(8):597-602.

33. Li Cl, Kardia SL, Liu CS, Lin WY, Lin CH, Lee YD, et al. Metabolic syndrome is associated with change in subclinical arterial stiffness: a community-based Taichung community health study. BMC Public Health. 2011;11:808.

34. Wang F, Chen HZ, Lv X, Liu DP. SIRT1 as a novel potential treatment target for vascular aging and age-related vascular diseases. Curr Mol Med. 2013; 13(1):155-64.

35. Biggeri A, Stanghellini E, Ruggeri M. Regression analysis of multiple outcomes. Epidemiol Prev. 2001;25(2):83-9.

36. Nikolopoulou A, Kadoglou NP. Obesity and metabolic syndrome as related to cardiovascular disease. Expert Rev Cardiovasc Ther. 2012;10(7):933-9.

37. Ghiadoni L, Penno G, Giannarelli C, Plantinga Y, Bernardini M, Pucci L, et al. Metabolic syndrome and vascular alterations in normotensive subjects at risk of diabetes mellitus. Hypertension. 2008;51(2):440-5.

38. Chen J, Muntner P, Hamm LL, Jones DW, Batuman V, Fonseca V, et al. The metabolic syndrome and chronic kidney disease in U.S. adults. Ann Intern Med. 2004;140(3):167-74. 
39. Weng C, Yuan H, Yang K, Tang X, Huang Z, Huang L, et al. Gender-specific association between the metabolic syndrome and arterial stiffness in 8,300 subjects. Am J Med Sci. 2013;346(4):289-94.

40. Dangardt F, Osika W, Volkmann R, Gan LM, Friberg P. Obese children show increased intimal wall thickness and decreased pulse wave velocity. Clin Physiol Funct Imaging. 2008;28(5):287-93.

41. Lurbe E, Torro I, Garcia-Vicent C, Alvarez J, Fernandez-Fornoso JA, Redon J. Blood pressure and obesity exert independent influences on pulse wave velocity in youth. Hypertension. 2012;60(2):550-5.

42. Sutton-Tyrrell K, Newman A, Simonsick EM, Havlik R, Pahor M, Lakatta E, et al. Aortic stiffness is associated with visceral adiposity in older adults enrolled in the study of health, aging, and body composition. Hypertension. 2001;38(3):429-33.

43. Corden B, Keenan NG, de Marvao AS, Dawes TJ, Decesare A, Diamond T, et al. Body fat is associated with reduced aortic stiffness until middle age. Hypertension. 2013;61(6):1322-7.

44. Mozos I, Luca CT. Crosstalk between oxidative and Nitrosative stress and arterial stiffness. Curr Vasc Pharmacol. 2017;15(5):446-56.

45. Joyce T, Chirino YI, Natalia MT, Jose PC. Renal damage in the metabolic syndrome (MetSx): disorders implicated. Eur J Pharmacol. 2018;818:554-68.

46. Mozos I, Malainer C, Horbanczuk J, Gug C, Stoian D, Luca CT, et al. Inflammatory markers for arterial stiffness in cardiovascular diseases. Front Immunol. 2017:8(1058)

47. Yuan SY, Breslin JW, Perrin R, Gaudreault N, Guo M, Kargozaran H, et al. Microvascular permeability in diabetes and insulin resistance. Microcirculation. 2007:14(4-5):363-73.

48. Piwkowska A. Role of protein kinase $\mathrm{G}$ and reactive oxygen species in the regulation of podocyte function in health and disease. J Cell Physiol. 2017; 232(4):691-7.

49. Wang CH, Chang RW, Ko YH, Tsai PR, Wang SS, Chen YS, et al. Prevention of arterial stiffening by using low-dose atorvastatin in diabetes is associated with decreased malondialdehyde. PLoS One. 2014;9(3):e90471.

50. Tran-Dinh A, Diallo D, Delbosc S, Varela-Perez LM, Dang QB, Lapergue B, et al. HDL and endothelial protection. Br J Pharmacol. 2013;169(3):493-511.

51. Scuteri A, Najjar SS, Orru M, Usala G, Piras MG, Ferrucci L, et al. The central arterial burden of the metabolic syndrome is similar in men and women: the SardiNIA study. Eur Heart J. 2010;31(5):602-13.

52. Meyer ML, Tanaka H, Palta P, Cheng S, Gouskova N, Aguilar D, et al. Correlates of segmental pulse wave velocity in older adults: the atherosclerosis risk in communities (ARIC) study. Am J Hypertens. 2016;29(1):114-22.

53. Tanaka H, Munakata M, Kawano Y, Ohishi M, Shoji T, Sugawara J, et al. Comparison between carotid-femoral and brachial-ankle pulse wave velocity as measures of arterial stiffness. J Hypertens. 2009;27(10):2022-7.

54. Sugawara J, Hayashi K, Yokoi T, Cortez-Cooper MY, DeVan AE, Anton MA, et al. Brachial-ankle pulse wave velocity: an index of central arterial stiffness? J Hum Hypertens. 2005;19(5):401-6.

\section{Ready to submit your research? Choose BMC and benefit from:}

- fast, convenient online submission

- thorough peer review by experienced researchers in your field

- rapid publication on acceptance

- support for research data, including large and complex data types

- gold Open Access which fosters wider collaboration and increased citations - maximum visibility for your research: over $100 \mathrm{M}$ website views per year

At BMC, research is always in progress.

Learn more biomedcentral.com/submissions 